\title{
A Link between Reactivity and Local Structure in Acid Catalysis on Zeolites
}

\author{
ADITYA BHAN AND ENRIQUE IGLESIA* \\ Department of Chemical Engineering, University of California at Berkeley, \\ Berkeley, California 94720 \\ RECEIVED ON AUGUST 3, 2007
}

\section{CON SPECTUS}

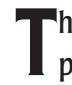
he extent to which spatial constraints influence rates and pathways in catalysis depends on the structure of intermediates, transition states, and active sites involved. We aim to answer, as we seek insights into catalytic mechanisms and site requirements, persistent questions about the potential for controlling rates and selectivities by rational design of spatial constraints around active sites within inorganic structures useful as catalysts. This Account addresses these matters for the specific case of reactions on zeolites that contain Brønsted acid sites encapsulated within subnanometer channels.

We compare and contrast here the effects of local zeolite structure on the dynamics of the carbonylation of sur-

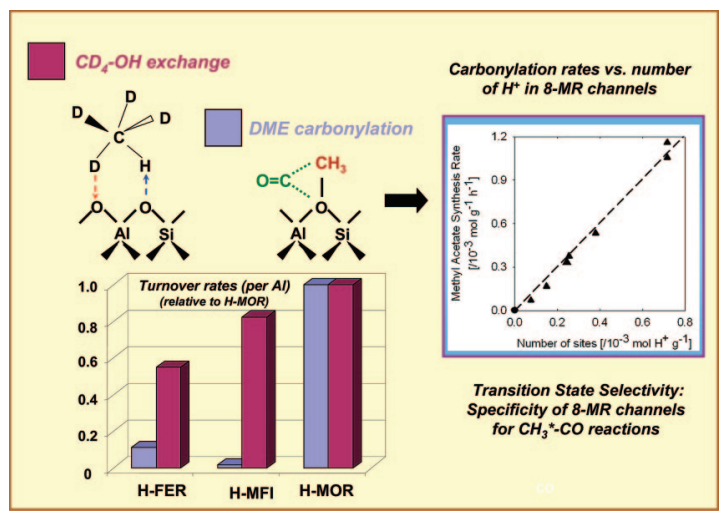
face methyl groups and of the isotopic exchange of $\mathrm{CD}_{4}$ with surface $\mathrm{OH}$ groups on zeolites. Methyl and hydroxyl groups are the smallest monovalent cations relevant in catalysis by zeolites. Their small size, taken together with their inability to desorb except via reactions with other species, allowed us to discriminate between stabilization of cationic transition states and stabilization of adsorbed reactants and products by spatial constraints. We show that apparent effects of proton density and of zeolite channel structure on dimethyl ether carbonylation turnover rates reflect instead the remarkable specificity of eight-membered ring zeolite channels in accelerating kinetically relevant steps that form ${ }^{*} \mathrm{COCH}_{3}$ species via $\mathrm{CO}$ insertion into methyl groups. This specificity reflects the selective stabilization of cationic transition states via interactions with framework oxygen anions. These findings for carbonylation catalysts contrast sharply the weak effects of channel structure on the rate of exchange of $\mathrm{CD}_{4}$ with $\mathrm{OH}$ groups. This latter reaction involves concerted symmetric transition states with much lower charge than that required for $\mathrm{CH}_{3}$ carbonylation. Our Account extends the scope of shape selectivity concepts beyond those reflecting size exclusion and preferential adsorption. Our ability to discriminate among various effects of spatial constraints depends critically on dissecting chemical conversions into elementary steps of kinetic relevance and on eliminating secondary reactions and accounting for the concomitant effects of zeolite structure on the stability of adsorbed reactants and intermediates.

\section{Introduction}

Zeolites are crystalline inorganic framework oxides with channel and pocket dimensions typically smaller than $1 \mathrm{~nm}$. Their constrained environments can be used to recognize molecules and promote specific transition states using shape or size as selection criteria; they are used broadly in practical applications of catalysis, ion exchange, and adsorptive separations. ${ }^{1-5}$ The advent of medium-pore zeolites, with ten-membered ring structural channels of $0.5-0.6 \mathrm{~nm}$ dimensions led to experimental evidence and theoretical interpretations of shape selectivity, through which topological effects on reactivity reflect in general geometric factors and more specifically the exclusion of molecules or transition states based on 
SCHEME 1. Carbonylation of Dimethyl Ether To Produce Methyl Acetate

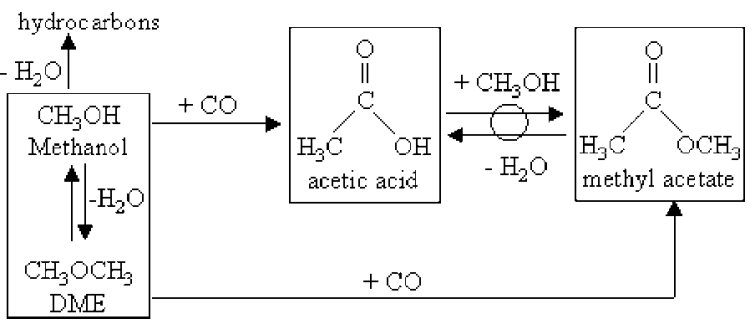

size. ${ }^{6-11}$ The strong effects of pore size and shape as they become "commensurate" with those of reacting species and the concomitant effects on enthalpies and entropies for adsorption and reaction have been noted broadly and convincingly; ${ }^{12-18}$ these effects become less noticeable when reactants, products, and activated complexes are significantly smaller than the spaces within which reactions occur. For highsilica zeolites (with sites of uniform acid strength ${ }^{19-21}$ ), with channels that allow facile entry and egress of reactants and products and within which transition states are not rigorously excluded by size, the local environment influences rates and reaction paths via subtle cooperative interactions that stabilize specific transition states. Theory has noted electronic perturbations in frontier orbitals of physisorbed olefins with increasing Al substitution in zeolites and with changes in pore topology, ${ }^{22,23}$ in the conformation and stability of bound alkoxides with local structure around the Al binding center, ${ }^{24,25}$ and in the energy of cationic transition states because of interactions with framework oxygen anions. ${ }^{26}$ Experimental verifications of these effects remain elusive and subject to contradictory interpretations, and specific effects of environment on transition states, without concurrent effects on reactants and products, have not been demonstrated by experiment or theory. As a result, the concepts of transition state, reactant, and product shape selectivity have remained intertwined. Our recent studies of dimethyl ether (DME) carbonylation catalysis (Scheme 1$)^{27-29}$ and hydrogen-deuterium $(\mathrm{H}-\mathrm{D})$ isotopic exchange focus on systems that allow a more precise delineation of zeolite-induced effects on the stability and dynamics of adsorbates and activated complexes and the deconvolution of these effects from concurrent adsorption and diffusion phenomena ubiquitous in zeolite catalysis.

\section{Zeolites as Microporous Hosts That Stabilize Cationic Intermediates}

Isomorphous substitution of Al for $\mathrm{Si}$ introduces a negative charge into crystalline silicates. Charge-compensating cationic species balance this charge and allow zeolites to stabilize cat- ionic intermediates, otherwise unstable in their unsolvated form, via interactions with anionic framework oxygens exposed at channel walls. The structure and spatial environment of these materials can also inhibit specific reactions, such as nucleophilic attack, by preventing effective overlap between electron pairs in the nucleophile and available orbitals in the electron-deficient moiety. We discuss here the specific case of catalytically relevant monovalent cations consisting of methyls or protons, the smallest stable species relevant to hydrocarbon catalysis.

\section{Surface Intermediates and Transition States Involved in Hydrocarbon Reactions over Zeolites}

Kazansky and Senchenya ${ }^{30}$ proposed that ethene forms covalently bonded ethoxides upon protonation via carbeniumion-like transition states. ${ }^{13} \mathrm{C}$ Magic angle spinning nuclear magnetic resonance (MAS NMR) studies have not detected carbenium ions as permanent species upon adsorption of propylene or 2-methyl-2-propanol in zeolites; ${ }^{31,32}$ these studies concluded that interactions between adsorbates and framework oxygen atoms were strong and that adsorbed species were best described as alkoxides, characterized by a C-atom bound to a lattice oxygen with $\mathrm{sp}^{3}$ hybridization. In general, strong Coulombic interactions between adsorbed species and the zeolite lattice substantially modify the geometry and reactivity of adsorbed surface species and result in stable intermediates that resemble covalently bound alkoxide intermediates. ${ }^{24,33-35}$ Theory has also suggested that transition states in hydrocarbon rearrangements are significantly charged on acidic zeolites ( 0.7-0.8 e), consistent with the qualitative success of arguments based on carbenium-ion chemistry in predicting the reactivity and selectivity for such catalytic reactions; these predictions reflect predominantly the ranking of activation barriers by carbocation stability instead of by the energies of the corresponding alkoxides. ${ }^{36}$ The development of rigorous descriptions of size and shape effects in zeolite catalysis requires the isolation of long-lived adsorbed intermediates (surface alkoxides) and a detailed assessment of the effects of local environment on the reactivity of these intermediates. These demonstrations have remained elusive for alkoxidemediated hydrocarbon catalysis because the complexity of the relevant reaction networks, often comprising hundreds of chemical reactions and elementary steps, makes the isolation of primary pathways a formidable task. Also, as discussed by Clark et al., ${ }^{37}$ the inability to explicitly account for spatial constraints imposed by the zeolite framework in terms of entropic and enthalpic contributions to the stability of inter- 
mediates and transition states, combined with the ensembleaveraging required because of the structural and chemical nonuniformity of zeolite protons, precludes the unambiguous assignment of reactivity differences among zeolites to perturbations induced by the simple encapsulation of reactants or transition states within zeolite cavities.

\section{Persistent Species Adsorbed in Zeolites}

Persistent carbenium ions have only been detected as bulky cyclic species, which delocalize charge effectively and for which steric constraints prevent direct covalent linkages with framework oxygen anions because of these constraints. Density functional theory (DFT) calculations indicate that these carbenium ions form on zeolites via electrostatic stabilization of ion pairs, but only for molecules with proton affinities above $\sim 870 \mathrm{~kJ} / \mathrm{mol}^{38}$ These cationic methylated benzene species have been implicated as the "hydrocarbon pool" in methanol homologation catalyzed by zeolites. ${ }^{39-41}$ Alkoxides (or carbenium ions) have not been isolated for smaller organic molecules at conditions relevant to catalysis, because these alkoxides equilibrate rapidly with their alkene precursors. The latter react rapidly via oligomerization, $\beta$-scission, and isomerization reactions that form and cleave $\mathrm{C}-\mathrm{C}$ bonds many times in the time required for the extraction of the surface intermediate via desorption as a stable molecule. These reactions lead to broad distributions of products formed from a common pool of gas-phase and adsorbed alkenes and make it difficult to establish the contributions from monomolecular and bimolecular pathways from selectivity data.

Surface methyls (methoxy species) are the simplest and most stable alkoxides; more importantly, they cannot deprotonate to a stable product. They have been widely implicated in putative, and often disputed, "direct" mechanisms for methanol homologation. These methyl groups are stable, small, and spectroscopically accessible; their inability to form a deprotonated product and their small size relative to the dimensions of zeolite cavities may allow a more rigorous assessment of the role of spatial constraints on the reactivity of alkoxide-type intermediates. Here, we compare the effects of zeolite topology on methyl and proton reactivity. Protons are the smallest counterion in zeolites; they are stable even above $773 \mathrm{~K}$ and are the species least likely to sense the topological features of their surrounding environment because of their small size.

Song et al. ${ }^{42}$ noted the stability and unreactive nature of methanol/DME derived $\mathrm{C}_{1}$-intermediates in homogolation reactions in the absence of a primordial hydrocarbon pool. A recent theoretical study probed $\mathrm{C}-\mathrm{C}$ bond formation from methanol-derived precursors and also concluded that all routes proceeding via bound methyls have inaccessible activation barriers. ${ }^{43,44}$ The routes rejected include those mediated by carbene intermediates in equilibrium with methyls $\left(\Delta E_{\mathrm{rxn}}=+240 \mathrm{~kJ} / \mathrm{mol}\right.$ for $\mathrm{Z}(\mathrm{O})-\mathrm{CH}_{3}$ deprotonation) and ylidetype species, which are unstable because of the weakly basic nature of framework oxygens. On SAPO-34, H-D scrambling between equimolar $\mathrm{CH}_{3}{ }^{*}$ and $\mathrm{CD}_{3}{ }^{*}$ mixtures preformed by $\mathrm{CH}_{3} \mathrm{OCD}_{3}$ dissociation was not detectable for periods over $2 \mathrm{~h}$ at $573 \mathrm{~K}$, and subsequent reactions with $\mathrm{H}_{2} \mathrm{O}-\mathrm{D}_{2} \mathrm{O}$ mixtures form DME with isotopically intact $\mathrm{CH}_{3}{ }^{*}$ and $\mathrm{CD}_{3}{ }^{*}$ groups, indicating that $\mathrm{C}-\mathrm{H}$ activation in methyls did not occur during reactions with dimethyl ether, methanol, and water at these temperatures. ${ }^{45}$

We have recently explored the carbonylation of DME at low temperatures (408-453 K) on Brønsted acids. Methyl acetate forms via rate-determining $\mathrm{CO}$ insertion into $\mathrm{CH}_{3}{ }^{*}$ groups; this step was probed by stoichiometric reactions of preadsorbed methyls with CO. All zeolites examined (H-MFI, H-MOR, H-FER) adsorbed $0.5 \pm 0.05 \mathrm{DME} / \mathrm{Al}$ upon exposure to DME at $423 \mathrm{~K}$, as expected from stoichiometric methylation of $\mathrm{Al}$ sites $\left(\mathrm{CH}_{3} / \mathrm{Al}=1.0 \pm 0.1\right)$, with the concurrent evolution of acidic protons as water. ${ }^{27}$ Infrared spectra showed that these methylation reactions weakened and ultimately suppressed $\mathrm{O}-\mathrm{H}$ stretching bands $\left(\sim 3600 \mathrm{~cm}^{-1}\right)$ and led to the concurrent emergence of spectral features assigned to $\mathrm{CH}_{3}{ }^{*}$ groups. These methyl groups persisted in dynamic vacuum at $423 \mathrm{~K}$ for $>1 \mathrm{~h}$, consistent with the presence and stability of $\mathrm{CH}_{3}{ }^{*}$ groups during carbonylation. ${ }^{28} \mathrm{CH}_{3} \mathrm{OCH}_{3}-$ $\mathrm{CD}_{3} \mathrm{OCD}_{3}-\mathrm{CO}$ mixtures led to fast methyl scrambling via unproductive methoxylation of $\mathrm{CH}_{3}{ }^{*}$ with DME (possibly via trimethyl-oxonium intermediates), without detectable isotopic dilution of methyl groups, as also found by Marcus et al. ${ }^{45}$ in their study of $\mathrm{H}-\mathrm{D}$ exchange for $\mathrm{CH}_{3}{ }^{*}-\mathrm{CD}_{3}{ }^{*}$ mixtures on SAPO-34 at $573 \mathrm{~K}$.

\section{Reactivity of Stable Surface $\mathrm{CH}_{3}{ }^{*}$ Species in Zeolites}

$\mathrm{CH}_{3}{ }^{*}$ groups can act as methylating agents in reactions with strong nucleophiles, such as water, methanol, and aromatics. ${ }^{46-49}$ Jiang et al. ${ }^{50}$ recently detected reactions of $\mathrm{CH}_{3}{ }^{*}$ with nucleophiles (e.g., amines, $\mathrm{HCl}$ ) in stopped-flow MAS NMR spectra of adsorbed products. The interactions of $\mathrm{CH}_{3}{ }^{*}$ groups with weak nucleophiles and the effects of zeolite topology in stabilizing required intermediates or transition states involved remain unexplored. Our recent studies have examined the effects of local environment on the reactivity of $\mathrm{CH}_{3}{ }^{*}$ with $\mathrm{CO}$, a prototypical weak nucleophile. 


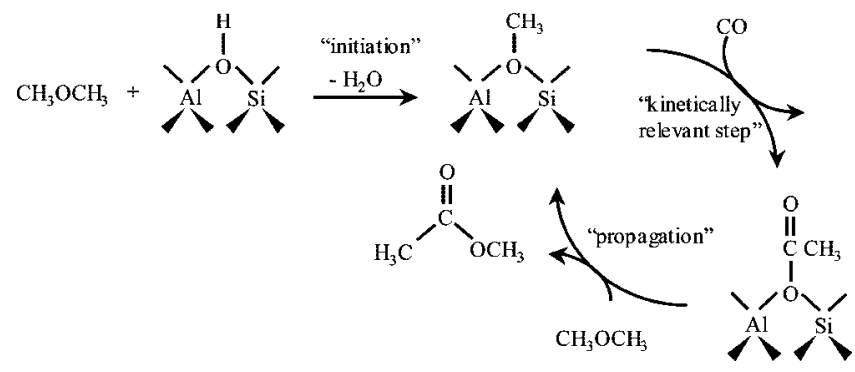

FIGURE 1. Proposed sequence of elementary steps for DME carbonylation to methyl acetate.

These measurements were carried out by methylating acidic zeolites with $\mathrm{CH}_{3} \mathrm{OCH}_{3}$ and then introducing $\mathrm{CO}$ to form surface acetyls, which upon reintroduction of DME (or DME-CO mixtures) lead to methyl acetate from acetyls formed during the intervening exposure of methyls to $\mathrm{CO}$. The methyl acetate formed after exposure to $\mathrm{CO}$ for various periods of time gives the number of stranded acetyls formed via $\mathrm{CO}$ reactions with $\mathrm{CH}_{3}{ }^{*}$ groups. These acetyls desorb (as methyl acetate) upon methoxylation by DME in a step that restores the methyl group used to form acetyl groups. These rates are similar (within a factor of 2 for H-MOR and H-FER) to steady-state DME carbonylation rates (per Al), consistent with $\mathrm{C}-\mathrm{C}$ bond formation via $\mathrm{CO}$ insertion into $\mathrm{Z}(\mathrm{O})-\mathrm{CH}_{3}{ }^{*}$ species in fully methylated surfaces as the sole kinetically relevant step in DME carbonylation. The persistence of surface methyls and acetyls, defined as their inability to desorb except by methoxylation reactions, allowed us to confirm their intermediate role within elementary steps during DME carbonylation cycles at steady state (Figure 1).

The reactivity of $\mathrm{CH}_{3}{ }^{*}$ species in carbonylation reactions differed markedly among zeolites. DME carbonylation turnover rates were much higher on $\mathrm{H}-\mathrm{MOR}\left(\sim 1 \mathrm{~mol}\left(\mathrm{~mol} \mathrm{H}^{+}\right)^{-1} \mathrm{~h}^{-1}\right)$ than on $\mathrm{H}$-FER $\left(\sim 0.1 \mathrm{~mol}\left(\mathrm{~mol} \mathrm{H}^{+}\right)^{-1} \mathrm{~h}^{-1}\right)$. Rates were nearly undetectable on H-MFI, H-USY, H-BEA, and mesoporous silicaalumina $\left(<0.03 \mathrm{~mol}(\mathrm{~mol} \mathrm{H})^{-1} \mathrm{~h}^{-1}\right)$. H-MOR samples from different sources or those with varying Si/Al ratio or Brønsted acid site density (e.g., by Na titration) gave methyl acetate synthesis rates (per $\mathrm{H}^{+}$) that seemed to increase monotonically with increasing $\mathrm{H}^{+}$density (and proximity). These trends appeared to contradict the uniform reactivity of zeolitic acid sites and the sole involvement of Al sites (and their associated protons) in the formation and reactions of $\mathrm{CH}_{3}{ }^{*}$ intermediates. ${ }^{28}$ These studies implicate a role of local zeolite structure on the reactivity of surface $\mathrm{CH}_{3}{ }^{*}$ species and, for MOR materials, reflect a range in reactivity of $\mathrm{CH}_{3}{ }^{*}$ groups (for reactions with $\mathrm{CO}$ ) depending on their location or on the number and proximity of Al centers within MOR structures.
H-MOR consists of twelve-membered ring (12-MR) main channels with intersecting 8-MR channels (side pockets), while H-FER contains intersecting 10-MR and 8-MR channels. The frequency shift for antisymmetric $\mathrm{O}-\mathrm{H}$ stretches in $\mathrm{H}-\mathrm{MOR}$ during adsorption of probe molecules of varying size was used to assign bands at 3610 and $3590 \mathrm{~cm}^{-1}$ to $\mathrm{O}-\mathrm{H}$ species in 12-MR and 8-MR, respectively. These assignments were then used to deconvolute the $\mathrm{O}-\mathrm{H}$ vibrational spectral features and to measure the number of $\mathrm{O}-\mathrm{H}$ groups in 8-MR, 10-MR, and 12-MR environments in acid and cation-exchanged forms of MOR and H-FER after adsorption of basic probe molecules of varying size. The $\mathrm{OH}$ bands in MOR became more symmetrical with increasing $\mathrm{Na}^{+}$content, because $\mathrm{Na}$ cations selectively titrate $\mathrm{OH}$ groups within 8-MR side pockets.

The effects of $\mathrm{H}^{+}$density and zeolite structure on DME carbonylation rates reflect the remarkably higher reactivity of $\mathrm{CH}_{3}{ }^{*}$ groups located within 8-MR relative to those within 10-MR (FER) or 12-MR (MOR) channels and the selective titration or removal of sites within 8-MR channels by titration with cations or by leaching, respectively. These strong effects of spatial constraints also led to low reactivity in catalysts containing only 10-MR, 12-MR, or mesoscopic channels (Figure 2). ${ }^{29}$ Such specificity of $\mathrm{CH}_{3}{ }^{*}-\mathrm{CO}$ reactions upon confinement appears to be unprecedented in catalysis by zeolites.

We ask next what accounts for the specificity of 8-MR channels in $\mathrm{CH}_{3}{ }^{*}-\mathrm{CO}$ reactions and, more generally, what other reactions and zeolite structures are likely to exhibit such sensitivity to spatial constraints. The specificity of 8-MR channels in $\mathrm{CH}_{3}{ }^{*}-\mathrm{CO}$ reactions may reflect a selective stabilization either of acetyl-like transition states or of CO molecules as they approach $\mathrm{CH}_{3}{ }^{*}$ groups. Concerted interactions of these carbocationic transition states with lattice oxygen anions within 8-MR channels may give rise to their selective stabilization within 8-MR channels relative to adsorbed $\mathrm{CH}_{3}{ }^{*}$ reactants and $\mathrm{CH}_{3} \mathrm{CO}^{*}$ products with significantly lower ionic charge. These reactants and products are predominantly stabilized by covalent bonds to vicinal framework oxygen atoms. This hypothesis suggests that these channel size effects will be much weaker for reactions involving less ionic transition states, such as isotopic $\mathrm{H}-\mathrm{D}$ exchange between $\mathrm{C}-\mathrm{H}$ bonds of alkanes and hydroxyl groups bound to zeolite Al sites.

\section{Role of Zeolite Topology in the Isotopic Exchange of $\mathrm{CD}_{4}$ with $\mathrm{H}$-Zeolites}

The smallest charge-balancing cation in zeolites is a proton. At high $\mathrm{Si} / \mathrm{Al}$ ratios $(>10)$, the acid strength of isolated $\mathrm{OH}$ groups, assessed from $\mathrm{NH}_{3}$ desorption data and Monte Carlo simulations of $\mathrm{NH}_{3}$ desorption is essentially the same in all 

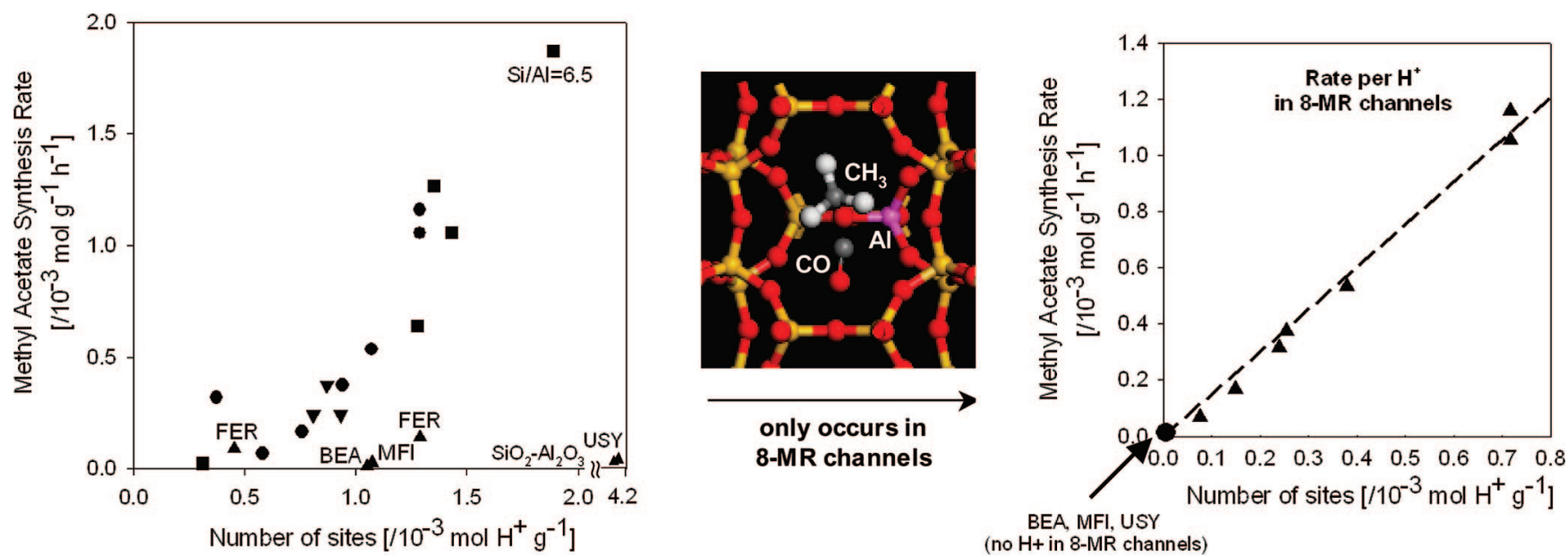

FIGURE 2. DME carbonylation rates plotted against the number of total $\mathrm{H}^{+}$sites in (i) $\mathrm{H}-\mathrm{MOR}(\mathrm{Si} / \mathrm{Al}=10$, Zeolyst) and cation-exchanged MOR samples (๑), (ii) H-MOR samples with $\mathrm{Si} / \mathrm{Al}=6.5$ and $\mathrm{Si} / \mathrm{Al} \approx 10$ (घ), (iii) H-MFI (Si/Al = 12.2), H-BEA (Si/Al = 12.5), H-USY (Si/Al = 3), amorphous silica-alumina ( $\mathrm{Si} / \mathrm{Al}=3)$, and $\mathrm{H}-\mathrm{FER}(\mathrm{Si} / \mathrm{Al}=10$ and 33.5) $(\mathbf{\Lambda})$ and (iv) $\mathrm{H}-\mathrm{MOR}(\mathrm{Si} / \mathrm{Al}=10$, Zeolyst) after dealumination by oxalic acid treatments $(\boldsymbol{\nabla})$. Details regarding experimental protocols can be found in refs $27-29$.

SCHEME 2. Proposed Mechanism for $\mathrm{H}-\mathrm{D}$ Isotopic Exchange between Alkanes and Hydroxyl Groups on Zeolites

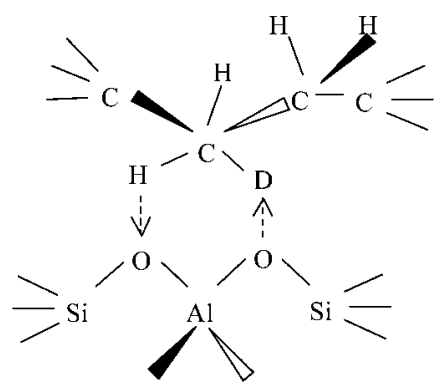

zeolites $\left(E_{\mathrm{NH}_{3}}\right.$ binding excluding nonspecific interactions with the zeolite lattice $\sim 120 \pm 10 \mathrm{~kJ} / \mathrm{mol}$ for MFI, FER, and MOR). ${ }^{21}$ Protons are also a spectroscopically accessible and isolated small moiety, the chemical dynamics of which may allow us to probe the reactivity of $\mathrm{H}^{+}$species in structurally related zeolite host environments and to ascribe pore-controlled reactivity in zeolites specifically to local effects of the zeolite environment on the potential energy surface sensed by reacting species along the reaction coordinate.

Hydrogen-deuterium isotopic exchange between $\mathrm{CD}_{4}$ and $\mathrm{OH}$ groups in Brønsted acids can probe the chemical properties of protons (Scheme 2) and often provides validation for theoretical treatments of reaction dynamics. ${ }^{51-53}$ Exchange involves the transfer of the proton in acidic $\mathrm{OH}$ groups to the $C$ atom in $C D_{4}$ in concert with the transfer of one $D$ atom from $\mathrm{CD}_{4}$ to a vicinal framework oxygen. The reaction coordinate is symmetric about the $\mathrm{O}-\mathrm{H}-\mathrm{C}$ and $\mathrm{C}-\mathrm{D}-\mathrm{O}$ bond centers; such processes have been proposed to occur via transition states with penta-coordinated carbon atoms and without significant charge separation. ${ }^{36,51}$ Thus, we explore next whether $\mathrm{OH}$ groups with varying local environments undergo isotopic exchange at markedly different rates and compare these effects of environment with those measured for DME carbonylation reactions.

The ability to deconvolute infrared bands for $\mathrm{O}-\mathrm{H}$ groups in 8-MR and 12-MR channels in H-MOR during isotopic exchange with $\mathrm{CD}_{4}$ allowed us to measure their respective rates of exchange with $\mathrm{CD}_{4}$. Isotopic exchange rates for hydroxyl groups in 8-MR and 12-MR channels of MOR are very similar (within a factor of 1.5 ) and do not show the remarkable specificity of 8-MR channels detected for $\mathrm{CH}_{3}{ }^{*}-\mathrm{CO}$ reactions (Figure 3).

The coverage of $\mathrm{CH}_{4}$-derived intermediates at $\mathrm{H}^{+}$sites is low at $\mathrm{H}-\mathrm{D}$ exchange temperatures ( 673 K). Neither higher hydrocarbons nor $\mathrm{CH}_{3}{ }^{*}$ infrared bands were detected during exchange, indicating that $\mathrm{CH}_{4}$ decomposition did not concurrently occur. The reasonable assumption that solvating effects of zeolite channels on activated complexes (involving a surface proton and a solvated paraffin) are similar to those on precursor states for $\mathrm{CD}_{4}-\mathrm{OH}$ reactions ${ }^{54}$ leads to rates rigorously proportional to intrazeolitic methane concentrations and to its pressure in the contacting fluid:

$$
r=k K P
$$

where $k$ is the intrinsic rate constant for $\mathrm{H}-\mathrm{D}$ isotopic exchange of $\mathrm{CH}_{4}$-derived intermediates and $K$ is the equilibrium adsorption constant for methane. Our infrared measurements on $\mathrm{H}-\mathrm{MFI}$ and $\mathrm{H}$-FER also give $\mathrm{CD}_{4}-\mathrm{OH}$ exchange rates $\left(\right.$ per $\mathrm{H}^{+}$) very similar to those on $\mathrm{H}-\mathrm{MOR}$, as shown by the rate constants in Table 1. The 5-fold (or lower) observed difference in the rate of isotopic $\mathrm{H}-\mathrm{D}$ exchange (per $\mathrm{H}^{+}$) among $\mathrm{H}-\mathrm{FER}, \mathrm{H}-\mathrm{MOR}$, and $\mathrm{H}-\mathrm{MFI}$ is in stark contrast with the 100- 


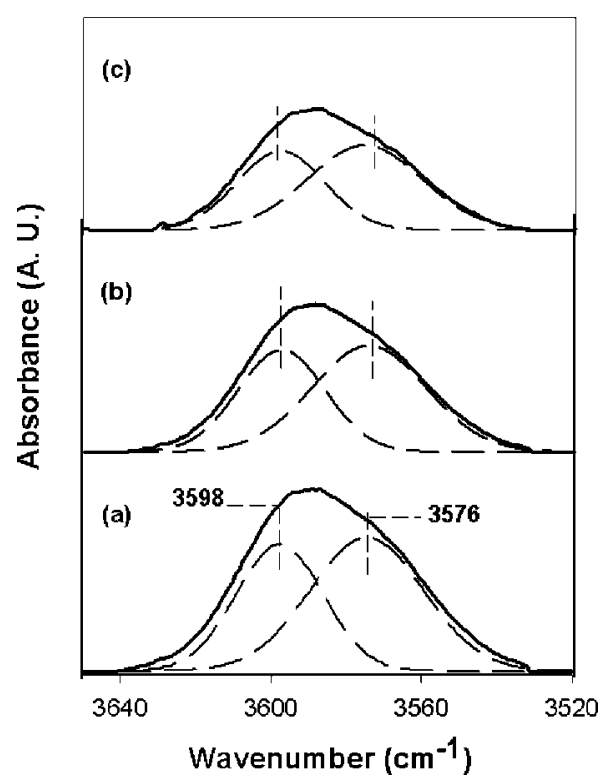

FIGURE 3. Infrared spectra ( - ) and deconvoluted bands corresponding to $\mathrm{H}^{+}$in 8-MR $\left(3576 \mathrm{~cm}^{-1}\right)$ and $12-\mathrm{MR}\left(3598 \mathrm{~cm}^{-1}\right)$ channels (---) of H-MOR (Si/AI $=10$, Zeolyst; $675 \mathrm{~K} ; 17.5 \mathrm{kPa}$ $\mathrm{CD}_{4}$ ) at (a) $0 \%$, (b) $20 \%$, and (c) $40 \%$ conversion of $\mathrm{OH}$ groups.

TABLE 1. First-Order Rate Constants in $\left[\mathrm{Pa}^{-1} \mathrm{~s}^{-1}\right]$ for $\mathrm{CD}_{4}-\mathrm{OH}$ Exchange for H-Form Zeolites As a Function of Temperature

\begin{tabular}{lrcc}
\hline \multicolumn{1}{c}{ zeolite } & pore structure & $k_{\text {app }}(\sim 673 \mathrm{~K})$ & $k_{\text {app }}(\sim 693 \mathrm{~K})$ \\
\hline $\mathrm{H}-\mathrm{MOR}(\mathrm{Si} / \mathrm{Al}=10)$ & 8-MR $\times 12-\mathrm{MR}$ & $7.0 \times 10^{-9 a}$ & $8.0 \times 10^{-9}$ \\
$\mathrm{H}-\mathrm{MFI}(\mathrm{Si} / \mathrm{Al}=12.5)$ & $10-\mathrm{MR} \times 10-\mathrm{MR}$ & $1.4 \times 10^{-9}$ & $6.6 \times 10^{-9 b}$ \\
$\mathrm{H}-\mathrm{FER}(\mathrm{Si} / \mathrm{Al}=10)$ & $8-\mathrm{MR} \times 10-\mathrm{MR}$ & $1.1 \times 10^{-9 c}$ & $4.4 \times 10^{-9}$
\end{tabular}

${ }^{a}$ Rate constant reported at $675 \mathrm{~K} .{ }^{b}$ Rate constant reported at $698 \mathrm{~K} .{ }^{c}$ Rate constant reported at $663 \mathrm{~K}$.

fold rate difference noted among these zeolites for $\mathrm{CH}_{3}{ }^{*}-\mathrm{CO}$ reactions.

Theory and experiment agree that $\mathrm{CD}_{4}-\mathrm{OH}$ exchange proceeds at similar rates (per Al, within a factor of 5 ) on zeolites with different structure. ${ }^{52,55}$ These rate differences reflect, at least in part, differences in the basicity of framework oxygens on zeolites with different channel structure and $\mathrm{Si}-\mathrm{O}-\mathrm{Al}$ angles; the sensitivity of $\mathrm{CD}_{4}-\mathrm{OH}$ to the environment containing the $\mathrm{OH}$ groups is, however, much weaker than those we have reported for DME carbonylation. Clearly, effects of zeolite pore size and connectivity on (adsorption and) catalysis, in turn, depend on the specific (adsorbate and) reaction chemistry.

\section{Mechanistic Pathways for Organic Reactions and the Influence of Zeolite Structure}

Reactions of organic compounds on zeolites involve the conversion of adsorbed species via cationic transition states, for which charge separation leads to unstable species and high activation barriers. ${ }^{24}$ This charge can be delocalized via inter- actions with vicinal framework oxygens; these nonlocal solvation effects decrease activation energies but depend sensitively on the local structure around intermediates adsorbed at Al sites. ${ }^{56}$ Thus, the ionic character of the transition state and the positioning of the "solvent" within zeolite channels determine how zeolite structure influences rates for a given elementary step. Theory has shown that strong cooperative effects with negatively charged zeolite lattice oxygen atoms and Brønsted acid sites with low proton affinity stabilize such cationic transition states. ${ }^{26,36}$ The effects of zeolite structure and of proton affinity are therefore expected to be much weaker for reactions proceeding via more covalent transition states, which resemble reactants involved in forming these transition states much more closely than for highly charged transition states. These conjectures and suggestions from theory have eluded experimental verification because the local shape of the pore influences not only transition states but also adsorbed reactants and products in elementary steps.

All $\mathrm{OH}$ groups in acidic zeolites (H-MFI, H-MOR, and H-FER) irrespective of their spatial environment form $\mathrm{CH}_{3}{ }^{*}$ groups and chemisorb DME $(0.5 \pm 0.05 \mathrm{DME} / \mathrm{Al}$ at $423 \mathrm{~K})$. The unreactive nature of $\mathrm{CH}_{3}{ }^{*}$ groups in $\mathrm{C}-\mathrm{H}$ bond activation at these temperatures and their inability to form desorbable stable molecules that restore protons makes these $\mathrm{CH}_{3}{ }^{*}$ stable species that desorb only upon reaction. $\mathrm{The}^{\mathrm{CH}_{3}}{ }^{*}$ band in H-MOR cannot be separated into contributions from sites in 8-MR and 12-MR channels of H-MOR, suggesting that any structural or electronic differences arising from their different local environment are spectroscopically undetectable. ${ }^{13} \mathrm{C}$ MAS NMR gives similar spectra for $\mathrm{CH}_{3}{ }^{*}$ groups in $\mathrm{H}-\mathrm{MFI}, \mathrm{H}-\mathrm{MOR}$, and H-FAU zeolites. ${ }^{46,47,50} \mathrm{CO}$ adsorbed on H-MOR at $123 \mathrm{~K}$ showed separable infrared bands for $\mathrm{CO}$ interacting with $\mathrm{O}-\mathrm{H}$ groups in 8-MR and 12-MR channels. Deconvolution of these $\mathrm{CO}$ bands showed that equilibrium constants for $\mathrm{CO}$ interactions with $\mathrm{OH}$ groups in 8-MR and 12-MR in H-MOR differ by less than a factor of 2 at $123 \mathrm{~K}$ (Figure 4); the enthalpic contributions to these differences in equilibrium constants will diminish at the higher temperatures ( $\sim 23 \mathrm{~K}$ ) relevant for carbonylation catalysis; thus, differences in equilibrium constants between 8-MR and 12-MR will be smaller than a factor of 2 at reaction conditions. Infrared spectra recorded at $123 \mathrm{~K}$ on methylated surfaces (prepared by dosing DME at $423 \mathrm{~K}$ and degassing to a dynamic vacuum $<10 \mathrm{~Pa}$ ) did not show any bands for $\mathrm{CO}$ species interacting with $\mathrm{CH}_{3}{ }^{*}$ groups, consistent with weak interactions of $\mathrm{CO}$ with $\mathrm{CH}_{3}{ }^{*}$-saturated surfaces. In light of the absence of spectroscopic differences commensurate with marked differences in observed rates (per Al) among different zeolites for reactants in the kinetically relevant 

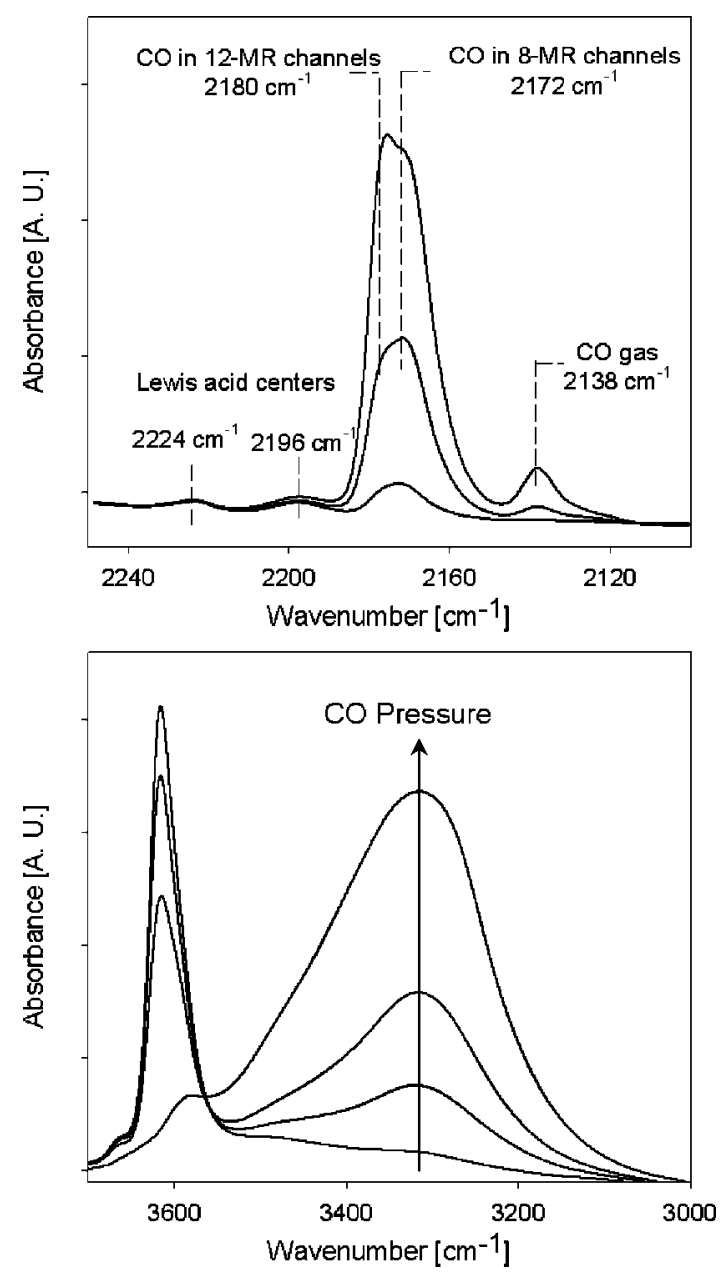

FIGURE 4. Infrared spectra of the (a) CO species (2100-2250 $\mathrm{cm}^{-1}$ ) interacting with hydroxyl groups of H-MOR $(\mathrm{Si} / \mathrm{AI}=10$, Zeolyst) and (b) OH stretching region $\left(3000-3600 \mathrm{~cm}^{-1}\right)$ upon $\mathrm{CO}$ adsorption at $123 \mathrm{~K}$.

$\mathrm{CH}_{3}{ }^{*}$-CO step, we suggested that the specificity of 8-MR channels for $\mathrm{CH}_{3}{ }^{*}-\mathrm{CO}$ reactions arises from selective stabilization of carbocationic transition states via interactions with framework oxygen anions. This stabilization is much weaker for larger 10-MR or 12-MR channels or for mesopores in nonzeolitic acids. In contrast, the reactant $\left(\mathrm{CH}_{3}{ }^{*}-\mathrm{CO}\right)$ and product $\left(\mathrm{CH}_{3} \mathrm{CO}^{*}\right)$ configurations are stabilized by covalent bonds with framework oxygen atoms; as a result, they are only weakly affected by more distant lattice oxygen atoms, the precise location of which varies with zeolite topology and ring size. The nonlocal ligating character of oxygen anions influences predominantly carbocationic transition states. ${ }^{56}$ The different interactions required to stabilize adsorbed reactant states and transition states may impair the accuracy of linear free energy relationships or of correlation of rates with zeolite acid strength for organic reactions occurring through highly charged transition states (charge on the activated complex of $\sim 0.7-0.8$ e). ${ }^{36}$
These effects of environment on carbonylation rates provide a marked contrast with the similar rates found for concerted transition states involved in $\mathrm{H}-\mathrm{D}$ exchange, which are less charged and more covalent in character (charge on the activated complex of $\sim 0.5$ e). ${ }^{36} \mathrm{H}-\mathrm{D}$ isotopic exchange rate differences can be ascribed instead to the (averaged) difference in basicity between the two lattice oxygen atoms that participate in the reaction and to the effects of the local zeolite structure in controlling the number of available oxygen atom pairs accessible for this reaction. Indeed, linear free energy relations based on proton affinity differences among neighboring lattice oxygen atoms have been used to describe reaction rates and to explain differences in $\mathrm{CD}_{4}-\mathrm{OH}$ reaction rates between $\mathrm{H}-\mathrm{MFI}$ and $\mathrm{H}-\mathrm{FAU} .{ }^{55}$ Hence, linear free energy relations can only be used to predict reaction rates of acidcatalyzed organic reactions when intermediates and activated complexes in the kinetically relevant step possess similar charge and are stabilized by interactions with the zeolite lattice requiring similar structural motifs.

\section{Outlook}

Our understanding of pore-controlled reactivity in zeolites, as well as our ability to use that understanding to develop new conversion technologies, has evolved rapidly over the past 40 years, from a handful of curious examples to their ubiquitous practice. $^{57}$ The continuous evolution of these concepts requires that we incorporate entropic and enthalpic effects that the pore structure has on intermediates and activated complexes along the entire reaction path. ${ }^{37}$ An obvious, but seldom used strategy, is to formulate rates in highly nonideal environments, such as those within zeolite channels, in terms of rigorous thermodynamic treatments. ${ }^{54}$ These thermodynamic nonidealities lead to alkane activation pre-exponential factors and activation entropies, seldom emphasized in these systems, that clearly depend on the properties (and solvation effects) of zeolite channels and of the acid sites that these channels circumscribe.

These entropic contributions reflect the role of zeolite topology in orienting (and preactivating) hydrocarbons. ${ }^{22}$ The critical role of entropy as channel occupation by adsorbed molecules increases has been specifically related to the ability of the zeolite structure to maximize effective length differences between linear and branched isomers. ${ }^{15} \mathrm{~A}$ more general description, however, must include the specific role of protons and cations in determining adsorbate configurations and the frequency and reactive success by which molecules encounter others within zeolite pores (Scheme 3). The importance of analogous orientation effects on the coordination 
SCHEME 3. Proposed Binding Modes for Alkanes with CationExchanged Centers in Zeolites (Similar to Those in Coordination Chemistry; Shown Here for $\mathrm{CH}_{4}$ )<smiles>[M][IH][CH]</smiles>

$\eta^{1}-\mathrm{H}$<smiles></smiles>

$\eta^{2}-\mathrm{H}, \mathrm{H}$

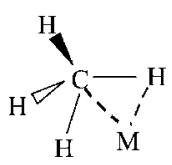

$\eta^{2}-\mathrm{C}, \mathrm{H}$ chemistry of saturated molecules is now being recognized ${ }^{58}$ and led Bercaw and Labinger ${ }^{59}$ to state that "the nature of the $\sigma$-complex will play a major, probably the major role in determining reactivity and especially selectivity in $\mathrm{C}-\mathrm{H}$ bond activation processes."

A related question, and possibly the one most relevant to our discussion here, is what volume of a zeolite pore does an adsorbate or an activated complex sample? These three-dimensional internal void spaces defined by the zeolite lattice may include channels, interconnections among channels, and large cages connected by smaller windows or channels. What diameter or size descriptor accurately captures the consequences of spatial constraints on reactivity within such complex volumes? ${ }^{60,61}$ How does the "activation volume" depend on molecular size, on whether the reaction is unimolecular or bimolecular, and on the size and charge of adsorbed reactants and their transition states?

Only a small fraction of the large number of currently available zeolites is used in practice. This reflects, at least in part, our emerging but incomplete knowledge about how such structures influence reactivity by solvating intermediates and activated complexes and by regulating the number and directionality of reactive encounters among molecules. Continuous progress in the development of these concepts will require experimental and theoretical approaches that probe these critical orientation and electronic descriptors. We will derive in return more robust criteria to design microporous materials that match the stringent spatial constraints required to direct catalytic pathways with the reactivity and specificity of biological catalysts.

\section{Summary}

Methyl and hydroxyl groups represent zeolite-surface species that are least likely to be perturbed by other effects induced because of confinement in molecular sized cavities and represent persistent cationic species that can only desorb by reaction. Our studies of the carbonylation reaction of surface methyl groups and $\mathrm{H}-\mathrm{D}$ isotopic exchange of hydroxyl spe- cies on zeolites probe and contrast the effects of encapsulation of transition state complexes with varying charge within zeolite micropores and in $\mathrm{CH}_{3}{ }^{*}-\mathrm{CO}$ reactions demonstrate a specific case where zeolite pore topology may engender changes in reactivity depending on critical charge and length scales. The rational design of improved zeolite catalysts is an important objective; this objective presupposes knowledge of reaction mechanisms and, in turn, fundamental descriptors of these mechanisms such as those we have discussed.

Financial support from BP as part of the $M C^{2}$ Program is acknowledged.

\section{BIOGRAPHICAL INFORMATION}

Aditya Bhan received his B. Tech. in Chemical Engineering from IIT Kanpur in 2000 and his Ph.D. from Purdue University in 2005 under the guidance of Professor W. Nicholas Delgass. Upon completion of his postdoctoral stay with Professor Iglesia, he will take up a position as Assistant Professor of Chemical Engineering and Materials Science at the University of Minnesota.

Enrique Iglesia is Chancellor Professor of Chemical Engineering at the University of California, Berkeley, and a Faculty Scientist in the E. O. Lawrence Berkeley National Laboratory. He received his Ph.D. in Chemical Engineering in 1982 from Stanford University. In 1993, he joined the Chemical Engineering faculty at Berkeley after eleven years at Exxon Research and Engineering. He is the Director of the Berkeley Catalysis Center and Editor-in-Chief of Journal of Catalysis. His research interests include synthesis and structural and mechanistic characterization of inorganic solids useful as catalysts for chemical reactions important in energy conversion, petrochemical synthesis, and environmental control.

\section{FOOTNOTES}

*Corresponding author. E-mail: iglesia@berkeley.edu.

\section{REFERENCES}

1 Venuto, P. Organic catalysis over zeolites: A perspective on reaction paths within micropores. Microporous Mater. 1994, 2, 297-411.

2 Corma, A. Inorganic solid acids and their use in acid-catalyzed hydrocarbon reactions. Chem. Rev. 1995, 95, 559-614.

3 Corma, A. Solid acid catalysts. Curr. Opin. Solid State Mater. Sci. 1997, 2, 63-75.

4 Davis, M. Ordered porous materials for emerging applications. Nature 2002, 417, 813-821.

5 Davis, M. New vistas in zeolite and molecular-sieve catalysts. Acc. Chem. Res. 1993, 26, 111-115.

6 Weisz, P.; Frilette, V. Intracrystalline and molecular-shape-selective catalysis by zeolite salts. J. Phys. Chem. 1960, 64, 382-382.

7 Weisz, P.; Frilette, V.; Maatman, R.; Mower, E. Catalysis by crystalline aluminosilicates. 2. Molecular-shape selective reactions. J. Catal. 1962, 1, 307312.

8 Kokotailo, G.; Lawton, S.; Olson, D.; Meier, W. Structure of synthetic zeolite ZSM-5. Nature 1978, 272, 437-438.

9 Derouane, E.; Gabelica, Z. A novel effect of shape selectivity - molecular traffic control in zeolite ZSM-5. J. Catal. 1980, 65, 486-489.

10 Csicsery, S. Shape-selective catalysis in zeolites. Zeolites 1984, 4, 202-213.

11 Derouane, E. Shape-selectivity in catalysis by zeolites - the nest effect. J. Catal. 1986, 100, 541-544. 
12 Santilli, D.; Harris, T.; Zones, S. Inverse shape selectivity in molecular sieves: Observations, modeling, and predictions. Microporous Mater. 1993, 1, 329-341.

13 Smit, B.; Maesen, T. Commensurate freezing of alkanes in the channels of a zeolite. Nature 1995, 374, 42-44.

14 van Well, W.; Wolthuizen, J.; Smit, B.; van Hooff, J.; van Santen, R. Commensurate freezing of n-alkanes in silicalite. Angew. Chem., Int. Ed. Engl. 1995, 34, 25432544.

15 Schenk, M.; Smit, B.; Vlugt, T.; Maesen, T. Shape selectivity in hydrocarbon conversion. Angew. Chem., Int. Ed. 2001, 40, 736-739.

16 Schenk, M.; Calero, S.; Maesen, T.; van Benthem, L.; Verbeek, M.; Smit, B. Understanding zeolite catalysis: Inverse shape selectivity revisited. Angew. Chem., Int. Ed. 2002, 41, 2499-2502.

17 Anderson, M.; Klinowski, J. Solid-state NMR-studies of the shape-selective catalytic conversion of methanol into gasoline on zeolite ZSM-5. J. Am. Chem. Soc. 1990 $112,10-16$.

18 Maesen, T.; Schenk, M.; Vlugt, T.; de Jonge, J.; Smit, B. The shape selectivity of paraffin hydroconversion on TON-, MTT-, and AEL-type sieves. J. Catal. 1999, 188, 403-412.

19 Olson, D.; Haag, W.; Lago, R. Chemical and physical properties of the ZSM- 5 substitutional series. J. Catal. 1980, 61, 390-396.

20 Barthomeuf, D. Zeolite acidity dependence on structure and chemical environmentcorrelations with catalysis. Mater. Chem. Phys. 1987, 17, 49-71.

21 Hunger, B.; Heuchel, M.; Clark, L.; Snurr, R. Characterization of acidic OH groups in zeolites of different types: An interpretation of $\mathrm{NH}_{3}$-TPD results in light of confinement effects. J. Phys. Chem. B 2002, 106, 3882-3889.

22 Zicovich-Wilson, C.; Corma, A.; Viruela, P. Electronic confinement of molecules in microscopic pores - A new concept which contributes to explain the catalytic activity of zeolites. J. Phys. Chem. 1994, 98, 10863-10870.

23 Corma, A.; Garcia, H.; Sastre, G.; Viruela, P. Activation of molecules in confined spaces: An approach to zeolite-guest supramolecular systems. J. Phys. Chem. B 1997, 101, 4575-4582.

24 van Santen, R.; Kramer, G. Reactivity theory of zeolitic Brønsted acidic sites. Chem. Rev. 1995, 95, 637-660.

25 Rozanska, X.; Demuth, T.; Hutschka, F.; Hafner, J.; van Santen, R. A periodic structure density functional theory study of propylene chemisorption in acidic chabazite: Effect of zeolite structure relaxation. J. Phys. Chem. B 2002, 106, 32483254.

26 Zygmunt, S.; Curtiss, L.; Zapol, P.; Iton, L. Ab initio and density functional study of the activation barrier for ethane cracking in cluster models of zeolite H-ZSM-5. J. Phys. Chem. B 2000, 104, 1944-1949.

27 Cheung, P.; Bhan, A.; Sunley, G.; Iglesia, E. Selective carbonylation of dimethyl ether to methyl acetate catalyzed by acidic zeolites. Angew. Chem., Int. Ed. 2006, 45, 1617-1620.

28 Cheung, P.; Bhan, A.; Sunley, G.; Law, D.; Iglesia, E. Site requirements and elementary steps in dimethyl ether carbonylation catalyzed by acidic zeolites. J. Catal. 2007, 245, 110-123.

29 Bhan, A.; Allian, A.; Sunley, G.; Law, D.; Iglesia, E. Specificity of sites within eightmembered ring zeolite channels for carbonylation of methyls to acetyls. J. Am. Chem. Soc. 2007, 129, 4919-4924.

30 Kazansky, V.; Senchenya, I. Quantum chemical study of the electronic-structure and geometry of surface alkoxy groups as probable active intermediates of heterogeneous acidic catalysts - what are the adsorbed carbenium ions. J. Catal. $1989,119,108-120$

31 Aronson, M.; Gorte, R.; Farneth, W.; White, D. ${ }^{13} \mathrm{C}$ NMR identification of intermediates formed by 2-methyl-2-propanol adsorption in H-ZSM-5. J. Am. Chem. Soc. 1989, 111, 840-846.

32 Haw, J.; Richardson, B.; Oshiro, B.; Lazo, N.; Speed, J. Reactions of propene on zeolite $\mathrm{H}-\mathrm{Y}$ catalyst studied by in situ variable temperature solid-state nuclear magnetic resonance spectroscopy. J. Am. Chem. Soc. 1989, 111, 2052-2058.

33 Haw, J.; Nicholas, J.; Xu, T.; Beck, L.; Ferguson, D. Physical organic chemistry of solid acids: Lessons from in situ NMR and theoretical chemistry. Acc. Chem. Res. 1996, 29, 259-267.

34 van Santen, R. Quantum-chemistry of zeolite acidity. Catal. Today 1997, 38, 377390.

35 Bhan, A.; Joshi, Y.; Delgass, W. N.; Thomson, K. DFT investigation of alkoxide formation from olefins in H-ZSM-5. J. Phys. Chem. B 2003, 107, 10476-10487.

36 Rigby, A.; Kramer, G.; van Santen, R. Mechanism of hydrocarbon conversion in zeolites. A quantum chemical study. J. Catal. 1997, 170, 1-10.
37 Clark, L.; Sierka, M.; Sauer, J. Computational elucidation of the transition state shape selectivity phenomenon. J. Am. Chem. Soc. 2004, 126, 936-947.

38 Nicholas, J.; Haw, J. The prediction of persistent carbenium ions in zeolites. J. Am. Chem. Soc. 1998, 120, 11804-11805.

39 Dahl, I.; Kolboe, S. On the reaction-mechanism for hydrocarbon formation from methanol over SAPO-34. 1. Isotopic labeling studies of the co-reaction of ethene and methanol. J. Catal. 1994, 149, 458-464.

40 Haw, J.; Song, W.; Marcus, D.; Nicholas, J. The mechanism of methanol to hydrocarbon catalysis. Acc. Chem. Res. 2003, 36, 317-326.

41 Arstad, B.; Kolboe, S. The reactivity of molecules trapped within the SAPO-34 cavities in the methanol-to-hydrocarbons reaction. J. Am. Chem. Soc. 2001, 123, 8137-8138.

42 Song, W.; Marcus, D.; Fu, H.; Ehresmann, J.; Haw, J. An oft-studied reaction that may never have been: Direct catalytic conversion of methanol or dimethyl ether to hydrocarbons on the solid acids HZSM-5 or HSAPO-34. J. Am. Chem. Soc. 2002, 124, 3844-3845.

43 Lesthaeghe, D.; Van Speybroeck, V.; Marin, G.; Waroquier, M. Understanding the failure of direct C-C coupling in the zeolite-catalyzed methanol-to-olefin process. Angew. Chem., Int. Ed. 2006, 45, 1714-1719.

44 Lesthaeghe, D.; Van Speybroeck, V.; Marin, G.; Waroquier, M. What role do oxonium ions and oxonium ylides play in the ZSM- 5 catalyzed methanol-to-olefin process. Chem. Phys. Lett. 2006, 417, 309-315.

45 Marcus, D.; McLachlan, K.; Wildman, M.; Ehresmann, J.; Kletnieks, P.; Haw, J. Experimental evidence from $\mathrm{H} / \mathrm{D}$ exchange studies for the failure of direct $\mathrm{C}-\mathrm{C}$ coupling mechanisms in the methanol-to-olefin process catalyzed by H-SAPO-34. Angew. Chem., Int. Ed. 2006, 45, 3133-3136.

46 Ivanova, I.; Corma, A. Surface species formed and their reactivity during the alkylation of toluene by methanol and dimethyl ether on zeolites as determined by in situ ${ }^{13} \mathrm{C}$ MAS NMR. J. Phys. Chem. B 1997, 101, 547-551.

47 Wang, W.; Seiler, M.; Hunger, M. Role of surface methoxy species in the conversion of methanol to dimethyl ether on acidic zeolites investigated by in situ stopped-flow MAS NMR spectroscopy. J. Phys. Chem. B 2001, 105, 12553-12558.

48 Blaszkowski, S.; van Santen, R. Theoretical study of the mechanism of surface methoxy and dimethyl ether formation from methanol catalyzed by zeolitic protons. J. Phys. Chem. B 1997, 101, 2292-2305.

49 Blaszkowski, S.; van Santen, R. Theoretical study of $\mathrm{C}-\mathrm{C}$ bond formation in the methanol-to-gasoline process. J. Am. Chem. Soc. 1997, 119, 5020-5027.

50 Jiang, Y.; Hunger, M.; Wang, W. On the reactivity of surface methoxy species in acidic zeolites. J. Am. Chem. Soc. 2006, 128, 11679-11692.

51 Kramer, G.; van Santen, R.; Emeis, C.; Nowak, A. Understanding the acid behavior of zeolites from theory and experiment. Nature 1993, 363, 529-531.

52 Schoofs, B.; Martens, J.; Jacobs, P.; Schoonheydt, R. Kinetics of hydrogendeuterium exchange reactions of methane and deuterated acid FAU- and MFI-type zeolites. J. Catal. 1999, 183, 355-367.

53 Jentoft, F.; Gates, B. H-D exchange between $\mathrm{CD}_{4}$ and solid acids: $\mathrm{AlCl}_{3}$ /sulfonic acid resin, promoted and unpromoted sulfated zirconia, and zeolite HZSM-5. Catal. Lett. 2001, 72, 129-133.

54 Madon, R.; Iglesia, E. Catalytic reaction rates in thermodynamically non-ideal systems. J. Mol. Catal. A: Chem. 2000, 163, 189-204.

55 Kramer, G.; van Santen, R. An ab-initio study of $D / H$ exchange between $\mathrm{CD}_{4}$ and the H-forms of zeolites FAU and MFI. J. Am. Chem. Soc. 1995, 117, 1766-1776.

56 Kazansky, V. The nature of adsorbed carbenium ions as active intermediates in catalysis by solid acids. Acc. Chem. Res. 1991, 24, 379-383.

57 Degnan, T., Jr. The implications of the fundamentals of shape selectivity for the development of catalysts for the petroleum and petrochemical industries. J. Catal. 2003, 216, 32-46.

58 Cobart, E.; Khaliullin, R.; Bergman, R.; Head-Gordon, M. Theoretical study of the ruthenium-alkane interaction in transition metal-alkane sigma-complexes. Proc. Natt. Acad. Sci. U.S.A. 2007, 104, 6963-6968.

59 Bercaw, J.; Labinger, J. The coordination chemistry of saturated molecules. Proc Natl. Acad. Sci. U.S.A. 2007, 104, 6899-6900.

60 Zones, S.; Harris, T. The constraint index revisited: Anomalies based upon new zeolite structure types. Microporous Mesoporous Mater. 2000, 35-36, 31-46.

61 Foster, M.; Rivin, I.; Treacy, M.; Friedrichs, O. A geometric solution to the largestfree-sphere problem in zeolite frameworks. Microporous Mesoporous Mater. 2006 90, 32-38. 